\title{
History and Development of Anthropology in the Arab World
}

\author{
Dr. Ali Z. Alzuabi \\ Dept. of Sociology \&Anthropology \\ Social Sciences College \\ Kuwait University
}

\begin{abstract}
This study documents the context of Anthropology as an academic enterprise in the Arab world, and the nature of its development over the last fifty years. It does not consider Anthropological studies conducted by foreign or non-Arab researchers about the Arab area. It aims to record the historical development of Anthropology in the Arab world by looking at the endeavors of its Arab pioneers, whether on the academic or on research level. This study focuses on the following questions: What did Anthropology represent in Arab societies? What was it expected to offer? How did Anthropology develop in the Arab world? What is the nature of the research contributions made by Arab Anthropologists? What impacts has Anthropology had on the structure of Arab society? What is the role of Anthropology in the new millennium? What role will Anthropology play in the Arab world in the coming years? This study was conducted using critical, historical, and descriptive methodologies, and this paper is organized into five sections. The first one discusses the origin and history of Anthropology in Arab countries. The second section explores the nature of the Anthropological inquiry and thematic foci in the Arab world while the third one discusses the impact Anthropology has had on the cultural and social structure of Arab society. Forth segment examines how Anthropology has developed in the Arab world, and the final one reflects the future of evolvement of Anthropology in the Arab world in the future.
\end{abstract}

Keywords: Anthropology, history of Anthropology, development, Arab world

\section{Introduction}

"Anthropology is the study of every aspects of human kind" (Jurmain, Kilgore \& Trevathan, 2009:6).Anthropologists aretrained to use investigative methodological tools and approaches to record societal changes and their impacts on Arab cultural structures. This paper explores the historical development of Anthropology in the Arab world; it does not consider research conducted by foreign Anthropologists or their studies on or about the Arab world, except those studies that were adopted by Arab researchers, and contributed to the development of Anthropology in the Arab world. Here, Anthropologyis considered as an academic discipline in Humanities and Social Studies' stream that has emerged in Arab universities over the last fifty years. During this short period of time, anthropology has become firmly established in university departments, institutions, and research centers throughout most of the Arab world.

Academic scholars subsequently published books, periodicals, Master's and Doctoral dissertations, and various other Anthropological articles centered on developing an Anthropological understanding of Arab social and cultural structures. More recently, Arab society has witnessed great transformations and unprecedented economic, social, and political changes. This paper reviews how the discipline of Anthropology evolved in the Arab region, discusses the scholarly works that were instrumental in its development, and anticipates Anthropology's continuing evolution in the Arab world. It is timely to reflect on what contributions the discipline of Anthropology might be expected to make to Arab society in this millennium. How Anthropology can add value to contemporary Arab community? What kinds of knowledge can this field of study provide? The structures and dynamics of Arab society — both hidden and visible- are best revealed in scholarly Anthropological studies. While Arab Anthropologists are true representatives of their own culture, they are also trained to be objective in their analyses. For these reasons, their researches are more authentic and legitimate than the findings of foreign researchers. The writings of professors of Anthropology, such as Ahmad Abozaid, Mohammad al-Johari, and Hussain Fahim, illustrate this viewpoint.

What has expanded the importance of Anthropological studies in the Arab world is that nowadays there is a tendency in many Arab countries to pursue innovation and promote technical, economic, and social development. However, some are afraid that modernization will lead to a distortion of traditional cultural structures. Hence, Anthropological studies are considered as means of protecting Arab cultural heritage from deformation. This heritage was documented by Arab Anthropologists who conducted ethnographic studies when traveling across lands and deserts disseminating scientific knowledge, studying the religions, emotions, habits, values, and cultures of the people they encountered (Ismael, 1997, pp. 312-317). 
A tenth-century Arab traveler named Ahmad ibn Fadlan was one such Anthropological and ethnographic intellectual pioneer. He studied groups of people in northwestern Europe, and Ibn Battuta (1304-1368/69) conducted pioneering research in China and the Far East. North Africa's IbnKhaldun (1332-1406) lived with and analyzed the social structure of desert Bedouin tribes, and his work predated the genesis of Anthropology as a bona fide scientific subject by centuries. Others whose work is significant are Ibnjubair, al-Masudi, Ali Idris, al-Istakhri, al-Bayrou, al-Yacoub, and al-Baghdadi (ibid., pp. 291-292).

This paper sheds light on Anthropology as an academic endeavor in the Arab world, by recording this discipline's historical development since it was first introduced in Arab societies and describing some of its research contributions in this arena. This paper diagnoses the state and status of Anthropological studies in the Arab world and examines the working conditions of Arab Anthropologists and their role in developing the discipline of Anthropology in Arab educational institutions and society.

In this paper I attempt to answer the following key questions:

1. What is the place of Anthropology in the Arab academy? How did it develop?

2. What is the nature of its preferred topics and research agenda?

3. What impacts has Anthropology had on the structure of Arab society? What is the future of Anthropology?

The methods used to answer these questions included the historical-critical method and a critical descriptive approach. The historical-critical method is used to explore the origin of Anthropology in the Arab world, its development, fluctuations, and controversies. It verifies that Anthropology is not merely a descriptive study or an analytical reading, but rather is grounded in the description, connection, and analysis. This method is useful in extracting Anthropology's origins and facilitating an understanding of its patterns of development. The strengths of this approach are optimized with the possible number of references to the primary resources and studies. This method was used to investigate how Anthropology first developed in the Arab world, by analyzing the texts of its early contributors, and thereby necessitating a critical reading that allows us to understand the impacts Anthropology has had on the structure of Arab society (Mohamad, 2003, p. 24). The critical descriptive approach was used to document the activities that accompanied the establishment of the first specialized department in Anthropology in universities in the Arab world, and the contributions of the Arab pioneers who studied the social and cultural factors of Arab society. This approach facilitates an understanding of Anthropology's place in the Arab world today and allows us to make projections about its future role (al-Awamlah, 1995, pp. 15-16).

\section{The History of Anthropology in the Arab World: Academic Origins and Contributions of Pioneers}

For purposes of this study, we will consider Anthropology from the perspective of an academic discipline. We will not be considering the thoughts of archaeologists and philosophers. When we say discipline or science, we mean a scientific field that is based on proven methodologies used for gathering evidence and establishing hypotheses. Anthropology's theoretical framework was developed in part through the cognitive crisis that characterizes the rise of any science. Although Anthropology has historical roots, it also had a specialized academic genesis about its western origins. This very fact made its subject content distinctive in the second half of the nineteenth century.

Some Arab researchers argue that Anthropology was introduced to the Arab world in the 1930s, under the name "Comparative Sociology Science," by a large number of British Anthropologists-including Evans Prichard, Hoa Karte, and Bristavi-who were teaching at an Egyptian University (al-Shammas, 2004, p. 169). Hence, Anthropology as a subject continued as a branch of Sociology in Egyptian Universities until the first independent department of Anthropology was established in the Faculty of Arts at Alexandria University in the 1974/75 academic year.

Richard Antoine, in his discussion of Anthropological studies in the Arab world, noticed an important fact about the early days of Anthropological studies in Egypt. In the 1930s, Egyptian universities hosted some outstanding British Anthropological scholars who lectured at Cairo University on a regular basis. One of these scholars was Evans Pritchard. Radcliffe-Brown was the first British scholar to come to Egypt as a professor of Anthropology in 1947. He came in response to an invitation by Alexandria University to establish the Institute of Sociology in affiliation with its Faculty of Arts. He held the position of chair of that institute in harmony with the then-prevailing Egyptian academic traditions. However, Anthropological studies in Alexandria University progressed under the influence of RadcliffeBrown, who considered it a major subject, and a branch of the Institute of Sociology. One of the most intelligent scholars to emerge from the Alexandria "school of Anthropology" was Dr. Ahmad Abozaid, who held the first chair of Anthropology established in Egypt in 1970 (al-Jawhari, 2005, pp. 5-6). Anthropological studies in Egypt were first introduced as an academic study in the 1970s. At this time, the number of chairs of Anthropology and the specializations in Anthropological research and dissertations multiplied, and the number of M.A and Ph.D. holders in Anthropology increased. 
A chair of Anthropology was subsequently put forwarded at Cairo University, and held by Ahmad Al-Khashab. Later, other Anthropological departments were established in the African Research and Studies Institute, and in the Faculty of Arts at Alexandria University. Anthropological studies commenced in Cairo University with the return of Dr. Ahmad al-Khashab from London University in 1953, where he had earned his doctorate, and so British traditions were introduced to Anthropological studies. In the mid-1960s, Dr. Atef Wasfi returned from the United States after studying Anthropology there, and at this juncture, American cultural traditions were introduced to the sociology department at Cairo University. Before and after that time, the efforts and various contributions of these professors' students and colleagues became numerous, which in turn led to the diversification and expansion of the Anthropological heritage at Cairo University, from where enlightenment transformed all parts of the university (al-Jawhari, 2005, pp. 6-7)?

In 1958, the National Center for Social and Criminal Studies (NCSCS) conducted a nominalization of a revenge killing using an Anthropological approach. This study led to the establishment of a center for Anthropology within the NCSCS; the most outstanding members of this school were Safia Qassim and Sami Abdulmonem, who worked under the supervision of Ahmad Abozaid. They subsequently became professors of Anthropology at American and Canadian universities. In 1959, Ahmad Abozaid presented a study funded by the World Labor office in Geneva on wandering nomads and semi-nomadic travelers in the Egyptian and Syrian deserts, after which many field studies were conducted in Middle Eastern deserts and North Africa in Morocco, Algeria, Libya, Jordan, Iraq, and Saudi Arabia (Saleh, 2002, pp. 109-112).

The Gordon Memorial College established in 1962 in Sudan aimed to offer high-quality education. Degrees were granted under the auspices and complete supervision of the London University, which set examinations, provided supervisors and evaluated results. Anthropology was not taught when the College was first established; rather, Anthropological studies were offered outside the College. Published studies were the most prominent Anthropologists in the world during that time. These studies became the classics of Anthropological science, beginning with an early study conducted by Seligman and his wife in 1909 on the tribes of the Sudan Nile and Evans Pritchard's research on the Nuer tribes from 1942 until 1958. These efforts advanced the development of Anthropology in Sudan and assisted in the establishment of structural and functional Anthropology, which linked Anthropology to history, and social sciences in particular, rather than the natural sciences. It was in contrary to the assumptions of structural functionalism theorists. These studies included the works of Pritchard on the Nuer, and Nadal's research on al-Nuba (Badawi, 2012, p. 136).

The College of Economic and Social Studies (CESS) opened in 1958 had departments of economics, social sciences, political sciences, and business administration. This College sought to produce a generational cadre of Sudanese scientists to grapple with the country's urgent social and economic problems. Given the scientific vision prevailing at the CESS, Anthropology continued to be taught in English until the early 1990s. The department of Anthropology then introduced high-quality cognitive programs and succeeded in preparing a generation of students who qualified to work at European universities, where they published many studies. Among them was Ian Cunnison on al-Baqaral (1966), Talal Assad on al-Kababeesh (1970), Fredrik Barth on the Omnia tribe (1993), and others.

The Sudanese model differed from the Egyptian model in many respects. First, social Anthropology was the first discipline in the social sciences and concentrated on studies of both Arab and non-Arab tribes inhabiting Sudan. Consequently, it represents a vivid icon of the cultural and ethnic blends evident across Africa, as exemplified in Sudan. There were factors which positioned Anthropological studies as a leading field in the British Empire. Other factors that shaped Anthropological inquiry in Sudan was specific aspects of the Sudanese cultural and social history and the configurations of hybridity that resulted from the mix of Arab and African tribes. Another difference between the Sudanese and Egyptian models was the Sudanese' use of the English language, which was the teaching language used by British and European professors, who in turn created the colonial basis that later formed the type of the social sciences in Sudan (al-Madani, 2007, p. 27).

Anthropology was first taught in Saudi Arabia in the 1976/77 academic year, in a new department of Sociology and Psychology in the College of Social Sciences in Emam Mohammad Ibn Saud Islamic University. Despite the significant recent expansion in university education in the Kingdom of Saudi Arabia, there is still no specialized academic department for Anthropology in any of the Universities in Saudi. There are, however, Saudi Anthropological researchers who have contributed Anthropological studies. These include Dr. Abo-Baker Baqader and Hassan Rashiq, authors of Anthropology in the Arab World (2012), and Dr. SaeedFaleh al-Ghamidi, who carried out many Anthropological studies, among them The Tribaland Urbanized Structure in the Kingdom of Saudi Arabia (1990). Thuraya al-Turki is the author of the most prominent of these studies, the Seriousness of Prosperity and Hardship: Family Transformation Between Two Periods (2006). 
These studies explored specific features of Saudi society including its rich and various subcultures and commented from an empirical scientific vantage point on the transformations and changes that occurred in Saudi society during the twentieth century, especially following the discovery of oil resources, and during the 1980s economic boom.

In Kuwait, the Department of Sociology and Social Work-established in the Faculty of Arts in the mid-1970s-is considered one of the oldest departments in Kuwait University. This department was integrated with the Psychology Department and then became an independent department in 1981. The department included a group of Arab and Kuwaiti Anthropologists, the most important of which included Dr. Mohammad al-Najar, Dr. Yousif Abo-Lyla, Dr. Mohib Shaban, Dr. Mohammad al-Hadad, and Dr. Yacoub al-Kandari. Dr. Yacoub al-Kandari conducted pioneer studies similar to his MA thesis titled, "The Social Functions of Al-Diwania in Kuwaiti Society" (1995), and his doctoral dissertation titled, "Relative Marriage and its Impact on the Marriage Agreement among al-Kandari Family in the Kuwaiti Society" (1998). He also published many studies in local and international scientific journals, such as Habits and Traditions Related to the Period of Death in Kuwaiti Society (2008), and Social Security in Kuwaiti Society (2006).

Mohammad al-Hadad has authored numerous studies on tribalism, tribes in the civil system, and on social and cultural change, in addition to his notable books titled, Contemporary Anthropology (2013) and Social and Cultural Change: The Theoretical Trends and their Explanation (2008). Hassan Ashkanani completed a doctoral dissertation on Archeology titled, "The Development of Pottery Industry and its Role in Trade During the Bronze Age from BC 30001200 in the Arabian Gulf and Neighboring Countries" (2014). Ali al-Zuabi has authored numerous Anthropological studies, beginning with his Master's thesis, titled "The Tribal System as Reflected in the Kuwaiti National Assembly Elections" (1994), Tackling Corruption in the Arab World (2007), Changing Societies: A Sociological Study of the Emergence of New Knowledge and Culture (2012), Civil Society in Kuwait: Challenges and Solutions (2012), and, The Participation of Kuwaiti Women in the Development Process (2016).

In Iraq, the age of Anthropology began very late compared to initiatives undertaken in other Arab countries. Baghdad University started teaching Anthropology in 1988 and introduced sociology and social work training. In the 2003/04 academic year, an independent Anthropology department opened in al-Mustanseriya University in Baghdad; it was the only department in the entire country to have this name. For this reason, Anthropologists had to demonstrate the field of study's application, and underscore its utility to the study of Iraq's society. It is evident that there were great problems and tensions associated with establishing a new teaching discipline intent on using its knowledge and expertise in aid of Iraqi society and the development of local societies. Its priority is to help people at the grassroots level to manage their affairs by studying the social characteristics of those groups, evaluating alternative strategies and visions, and drawing up developmental plans and programs that could be used to mitigate local societal and environmental problems.

Hence, in Iraq, Anthropology dealing with broader perspective of Iraq was separated from the body of Anthropology produced locally that was more of "applied" in nature. In conjunction with this structure, foreign expat researchers introduced imported directions, and a local endeavor was led by a group of Iraqi Anthropological researchers. The most outstanding figure in Iraq is Dr. Shaker Mustafa Salim, who, through his academic efforts in research, translation, and publications, was truly the creator of an Iraqi Anthropology discipline. He translated a book by his former UK Anthropological professor, Lucy Mere, titled Social Anthropology (1983). Qais al-Nouri's 1964 dissertation "Struggle and Persistence, the Cultural Understanding of Iraqi Kildanese" represented another step in how to study and understand social, cultural, economic, and political aspects of ethnic groups within the society. Al-Nouri's research and publications, coupled with his remarkable translations of social scientific research into Arabic, represent a turning point in the evolution of Iraqi Anthropology. Qahtan al-Nasseri studied agricultural reforms in an Iraqi village (1978), and Aladin al-Bayati investigated the relationship between the countryside and the city. Dr. Saeed Faydhy also provided a good understanding of Anthropology in his textbook titled, The Study of Anthropology.

The situation of Anthropology differed substantially between al-Maghrib al-Arabi (Mauritania, Morocco, Algeria, Tunisia, and Libya) and the other Arab countries previously described. In Algeria, the first country where North Africa was occupied as a French colony, eyes were directed to untouched regions such as Oras and the Mizab tribes. When conditions permitted, researchers went deep into the deserts. Tunisia also embarked on ethnographic studies during this time, when there was a focus on subjects and topics that were similar to those attracting research in Algeria and Morocco. This constituted the most active laboratory in early ethnographic studies andwas represented by works on tribal groups. These efforts were crowned by several outstanding works in Algeria, in a range of journals from that time such as the African Journal, launched in 1856, the Tunisian Journal in 1864, and Hisbari'sin Morocco in 1921 (Kossa, 2015, p. 25). The Anthropological projects ceased after the al-Maghrib al-Arabi countries achieved independence. 
Hencethey were not considered as being representative of an independent scientific specialization of the improved academic practices in universities. Only a few researchers had the opportunity to obtain higher degrees in Anthropology, especially at universities in France, Great Britain, and the United States.

In Algeria, Anthropological knowledge expanded gradually with the opening of Anthropology departments in some Algerian universities in the 1970s. In Tunisia, Anthropology did not attract sufficient interest, so it did not achieve independent academic status as a specialization to be taught at universities. This situation was somewhat similar to that in Al-Maghreb Al-Arabi in particular, and more generally to that in other countries in the Arab world (Kossa, 2015, p. 38). The most prominent pioneers of Anthropology in al-Maghreb al-Arabi were AbdulqaderBakhoosh and Hassan Jilly in Algeria, Salim Darnoni and Mohammad al-Haj Salim in Tunisia, and the social Anthropologist Mohammad Alal-Sagheer Jinjar in Morocco.

In general, Anthropological activities in al-Maghrib al-Arabi were not a response to social demands or needs, but were a response to an urgent need sparked by their encounter with Anglo-Saxon Anthropology, and a growing realization of the need to understand the various cultural phenomena pertinent to the tribes, rituals, political order, and religions that characterized the post-colonial period.

In Balad al-Sham (Syria, Lebanon, and Jordan), Levant Anthropology emerged at a later stage. In Syria, Anthropology was considered a very innovative science in the Syrian universities, though teaching is still limited within the sociology department, and the field is devoid of specialists. One of the most outstanding pioneers is Sulaiman Khalaf, whose MA thesis was on tribal leadership and policies in northeastern Syria (1975), and whose doctoral dissertation (1981) examined economic and social transformations in the contemporary Syrian countryside. In Lebanon, Fuad Ishaq alKhouri was one of the Anthropological pioneers. He published Anthropological studies, beginning with his doctoral dissertation, based on his fieldwork among the immigrant Lebanese in Sierra Leone in West Africa in 1964. His other publications include his remarkable book, The Arabic Mentality (1998). In Jordan, the most prominent contemporary scholars in the Anthropological inquiry are Mohammad Sulaiman Shunaq and Abdallah al-Sharman. The subjects studied center on religion and ritual, Levant marriage customs, and applied aspects of tourism in the context of the Kingdom of Jordan.

Contemporary Arab Anthropologists have contributed a range of important research studies. For example, the studies of al-Essa on some villages in Egypt, al-Zandi tribes in Sudan, al-Qabari in Alexandria and among the Arab tribes in Burqa, Ahmad Abo-Zaid and his studies on Middle Eastern societies and North Africa, or in some East African countries (Uganda and Tanzania), or in West Africa (Nigeria and Sierra Leone), between 1965 and 1970. Ahmad alKhashab conducted a field study of clans and closed groups in Iraq in 1970, and Moheydeen Saber researched the alZandi in South Sudan and was involved in a field survey with other Arab Anthropologists on the Bedouin and Bedouinism in Saudi Arabia, Kuwait, Qatar, and the United Arab Emirates, between 1962 and 1972 (Ismael, 1977, p. 312).

\section{Principal Anthropological Subjects Researched in the Arab World}

Although contemporary Anthropology encompasses many subjects with different scientific sub-disciplines, what has generally become apparent since the rise of this discipline is that the first Anthropological scholars focused on the "primitive" societies such as Native Americans, Australian indigenous peoples, and societies in the South Pacific and sub-Saharan Africa (al-Mikawi, 2008, p. 10).

Anthropologists in the Arab world moved beyond this traditional perspective of Anthropology, and directed their studies toward various subjects, concentrating on many details related to the Arab social and cultural environment and its real life and circumstances. Consequently, Arab interest in Anthropology was manifested in publications of a broadranging nature on human civilization, and Anthropological concepts and their application in the social and cultural studies. These included Ibrahim Zarqana's Anthropology (1959), Mohammad Riyadh's Man: A Study in Gender and Civilization (1974), Hussain Moenis' Civilization: A Study in Its Origin and Creation and Factors of Decline (1978), Ahmad Abo-Zaid's Social Structure: Introduction to Study the Society (1980), Safouh Al-Akhras' Social Anthropology (1984), and Ali al-Jibawi's Anthropology-Science of Mankind (1997). also, some field studies were conducted by a few Arab researchers in various areas of the Arab world. These studies were published in Arabic scientific periodicals, such as the Intellectual World Journal, issued by the Ministry of Information, Kuwait, the Arab Future Journal, issued by the Arab Unity Studies Center, Beirut, and the Contemporary Arabic Thought Journal, issued by the Arabic Development Center in Beirut and Paris. Journals were also published by the faculties and colleges of arts and human sciences in Arab universities, and conferences, such as the pre-conference preparatory meeting held by the International Anthropology Sciences Union in Egypt (al-Shammas, 2004, pp. 174-175). 
Moreover, we now find new readings and topics exploring marriage and kinship in contemporary Arab society which is considered one of the subjects of Anthropological research in general. These studies recorded the changes taking place in marriage practices and marked the rapid transformations occurring in many aspects of family and its structure. This can be clearly seen in "external marriage", type of marriage where marriages out of the equal social group but within the same religion. For example, the category of people who prefers external marriage include modern, depends more on economic and cultural class similarities, are interested in family relationships, and independent from new family's housing and living conditions. It leads to inter-generational ruptures in the continuity of evolving family life traditions and customs.

The fields of research and study expanded in the discipline of Anthropology, and the subjects examined were integrated with other science topics, and particularly the sciences of Biology, Sociology, and Philosophy. In addition to its theoretical and applied approaches under its fields and specializations, in recent years we havewitnessed rapid and significant changes that have impacted societies, and people's lives as individuals. Although Anthropology is concerned with the study of humankind, just like other human sciences, it is basic structure which serves its interest in facilitating improvements and development (ibid., p. 8). The key pioneering Anthropologists who conducted carried out researches in Kuwaiti society includeYacoub al-Kandari, Mohammad al-Hadad, Hassan Ashkinani, MahaSejari, JasimDyab, Majed al-Muteri, Ali al-Zuabi, and Mesaed al-Nasim.

Anthropologists of the Arab world have indicated that the subject of greatest importance in the field of Anthropology in this challenging age is the "civilization", whirlpool that organizes our modern world. When we tabulate the issues and subjects that have occupied Anthropology in the Arab world and become the subject of media attention and intellectual and scientific conferences, we note that the origins of these problems lie mainly in the pressure resulted from rapid social and cultural changes. Villages and countryside shave been transformed into urban metropolises, industrialization have left its mark in the commercial, occupational, and educational fields. Accordingly, social and psychological forms have impacted individuals and family lives in Arab cities. Although problems of poverty, illiteracy, and the spread of diseases have been present throughout the history of the Arab world, they have declined markedly by virtue of the economic progress, and the tangible development of preventive healthcare over the past two decades (al-Nouri, 1985, p. 7). On the other hand, Al-Zuabi (1999) presented an Anthropological study that endeavored to explain and interpret the influences of urban processes on (1) contemporary tribal structures in cities, and (2) marriages systems of tribal groups of Kuwaiti society during the last fifty years.

The Arab world has thus witnessed the addition of a new agenda to the list of subjects that were previously explored as part of Anthropological research. For example, we find the Egyptian Anthropological studies in the 1970s concentrated their interests on studying Egypt's social and economic problems, and rapid population growth, family and its organization, urbanization, industrialization, and the settlement of peasants on reclaimed lands (al-Jawhari, 2005, p. 9). The concept of culture itself is considered as one of Anthropology's most important contributions to human reflection. As Clyde Kluckhohn (1949) wrote, culture positions Anthropology before the eyes of humanity, functions as a mirror that gives an image of humankind, and, at the same time, contributes to our knowledge of the origin of the society, its nature, functions, and organization. Consequently, Anthropology's influences are apparent in the fields of philosophy, literature, and politics. Within the framework of the current situation, we find that most Arab countries have achieved modernization and progress in the economic, social, and technological spheres, without harming the values, religious teachings, or the bases of social heritage and original traditions. Anthropologists played an important role in documenting this heritage, studying those traditions, and in the revival of Arab civilization. By analyzing the concepts of cultural Anthropology and the application of field studies, Arab Anthropologists can perform a role in the development of research projects (Fahim, 1986, p. 268).

If we examine the concept of tribe, we find that it occupied an essential position in Arab Anthropology, as described by Ernest Gellner and others, for identifying the social entities of different life structures and forms (al-Shammas, 2004, p. 173). The Anthropological studies that were conducted under this project were numerous and unconstrained. For example, each tribe's habits, traditions, customs, folklore, and dialects comprise a fertile territory for possible Arab Anthropological projects and studies. Abo-Baker Baqader and Hassan Rashiq emphasized the fact that Archeological studies, both qualitative and quantitative, and especially those that were concerned with the Eastern regions of the Arab world, represent a broad scientific field. It constitutes a substantial historical treasure because the Archeological studies in this region were related to interests and issues in the area's classical studies. Here, ancient history witnessed the creation of religious groups and empires that formed all the subsequent historical stages (Baqader and Rashiq, 2012). With their entry into the twentieth century, many Arab Anthropologists shifted their interests from contemplating solutions to identified problems, and to apply their knowledge to solve real problems (al-Shammas, 2004, p. 9). 


\section{The Impacts of Anthropology on Arab Social Structure}

Academic institutions in most Arab countries have witnessed the establishment of scientific departments that specialize in Anthropological and social studies since 1960s, some of which were created in cooperation with prestigious, wellestablished Western academic institutions, or under the supervision of outstanding scholars like Evans Pritchard. He developed the well-known thesis of al-Nuwair in Sudan, which became a reference and baseline for much later research in social studies and contributed to the establishment of an Anthropology department at Alexandria University. As a result, Arabic Anthropological literature developed as the department grew. Anthropological studies were in general concerned with introducing a subject's pedagogy, rather than carrying out scientific research that studied local societies in Situ. Despite the absence and poverty of theory in Arab academic institutions, it largely depended on imported Western social theories and concepts by various pioneering popular Arab Anthropologists who contributed in multiple ways to a better understanding of Arab society and its structure (Baqader and Rashiq, 2012).

Despite the confusion of some European intellectuals regarding the effect of Arab cultural heritage on modern Western civilization, a trend to rejoice in this historical fact dominated, and countered any attempt to obliterate or underestimate its role. The European imperialistic movement that occurred in the Arab and Islamic world supported this negative attitude and emphasized the inability of Arabs and Muslims to achieve innovation and creativity or to contribute to human civilization. This very fact fueled a sense of "estrangement" and "alienation," an issue in conjunction with developments and advancements in the modern age. It is, therefore necessary to thoroughly examine and study Arab heritage with all its diversifications and richness. Works directly related to Anthropology such as the work of Ahmad IbnMiskawy on evolution and the transformation of living things deserves particular attention. These studies may reinvigorate the history of Anthropology, or at least ensure that its methodological and cognitive origins are retained. There remain numerous concepts about the human race and civilization, and aspects of daily life and its problems, which still occupy in the mind of contemporary Anthropological researchers in the Arab world (Fahim, 1986, p. 259).

If we examine the history of the relationship between Western Anthropological thought with the culture of Arab society, we find that Evans Pritchard and Ernest Gellner are the most important Anthropologists who dealt with the culture and societies of the Arab world. These scholars, deeply rooted in Western and contemporary European cultures, sought to understand the social and cultural aspects of Arab world and its Islamic characteristics which are different from Western cultural and social conceptions and structures. This is known as "clash of civilizations" (Huntington, 1996). The heart of Ernest Gellner's abiding interest in this regard was not only the ethnographic details that distinguish Arab culture and society but the need to study the logical mechanisms and laws that underlie the Arab world's social system. Gellner, the Anthropologist, and philosopher, through his ethnological and Anthropological studies, analyzed two important aspects that later became the basis of Anthropological research in the Atlas Mountains in the Arab West. He examined the concept of separatism with an eye to the functions of the family and the clan, Bedouinism, Arabization, and folklore where separatism is the most prominent structural law of kinship and political systems in Arab tribal societies. Evans Pritchard studied local factors that helped to re-balance the scales of tribal separatism as he viewed the role of Islam since it is an ideological system manifested in the social organization of Burqa citizens (Libya), which is the Salwasi Sophist movement (Wasfi, 1971, p. 170).

On the other hand, al-Shammas (2004, pp. 172-174) attributed the rejection of Anthropology and its dissemination in the Arab world to two events. The first was the rejection of the idea of biological development since this contradicts religious thought and its explanation of theuniverse which emphasizes that Man is the creation of Allah, rather than the product of developmental cycle of biological origin. Some Arab intellectuals, however, called for a compromise between the two ideas and extracted from both what was beneficial for science. al-Shammas (2004, p. 170) described the situation of Abdallah Nasif in The Physical and Social Sciences as there is no contradiction between religious beliefs and human scientific knowledge used for the good of humanity. Al-Shammas also wrote in This Age and Its Culture that scholar ZakiNajeeb Mahmoud mentioned that what religion traditionally asserted is indeed what science has discovered in the modern age. It is the ability to show us how we can use religious faith to motivate us to develop a new scientific understanding that has value for humanity. The second event was the link of Anthropology's origins and historical beginnings to imperialism and the studies carried out on "backward" societies to clarify their structures and nature of culture. They were used to facilitate colonization at a time when Arab society was suffering from occupations and imperialism and endeavoring to achieve liberation and development. Thus, dealing with any European or Western interest in Arab world and their cultures lies within the circle of imperial greed or conspiracy against the Arabs. Hence, any Westerner showing interest in these topics became suspect in the Arab world (ibid., 175). Despite the expansion of Anthropological studies to different human societies, some obstacles prevented Arab Anthropologists from investigating social, cultural, political, and economic issues of Arab societies. These limitations are because of the fact that Arab societies are strictly closed. 
In general, we can say that the emergence of Anthropology occurred late in the Arab world. However, some writings were more effective in some countries than others, and especially in Egypt, where Anthropologywas first introduced in universities. For example, you may not find any studies on some topics in certain countries, and particularly studies that were carried out by foreign researchers. This dearth of studies may be attributed to the legal and research procedures determined and imposed by each country. There are many considerations other than the academic ones that assess which topics of inquiry will be deemed useful or even permissible. Perhaps, the most important question to answer is how we can accept respected studies that contain important information about our region's policies. Although some of these studies were translated into Arabic, those translations were not subjected to critiques and analysis and did not find their way into university courses. Despite the contributions of some local Anthropologists to these studies, including their participation in the criticisms, most of this work was undertaken in non-Arabic languages outside the Arab World. Hence, these Anthropological studies represented the perspective of a Western enterprise of knowledge production, and largely reflected a center of ambition and interest by researchers outside the Arab world. Specialists in the social sciences should not view this situation as political or ideological. it can be understood as a tradition inherent in the concepts related to university studies and the books used to teach the students. Although these studies satisfy the educated populace's need for cultural content, we do not find solid,informed critiques of these studies in contemporary Arab Anthropological literature (Baqader and Rashiq, 2012).

\section{The Development of Anthropology in the Arab World}

Over the past two decades, there have been increasing calls to clearly define the role of the Arab researchers in the field of Anthropology, and their possible contributions to addressing current problems and crises, and particularly those in their own countries, rather than relying on imported Western models. Hussein Fahim responded to this call and undertook"Anthropology of the original citizens." In 1978 he organized a symposium in Austria that was considered a milestone and recognized those researchers who had directed their studies toward achieving concrete benefits for their people and societies. AnthropologistThurya al-Turki explained how she attained a model of perspective that was tied to the situation of women in Arab societies, one that contradicted the common Western model that pertained to the same position. She emphasized that this work had been made possible by a researcher who was an "insider" in these societies, and able to understand their social organization (Ibrahim, 1997, pp. 235-36). Thus, the development of Arab Anthropology is related to the capabilities and desires of its researchers to conduct more Anthropological studies on Arab societies, to understand the changes and transformations these societies are now undergoing.

Some of the issues confronting Arab Anthropologists are conceptualized under the following points drafted by alShammas (2004, p. 173);

1) Anthropological studies should concentrate on the everyday lives of their subjects, instead of representing formal viewpoints provided by officials.

2) Anthropological analyses of the social environment should not concentrate on the ideal thoughts as models. they should investigate the changeable models of social relations and conditions, and especially what is called a political economy.

3) In Middle Eastern societies, "political economies" and "social realities" are not necessarily interconnected. Therefore, Arab Anthropologists must be careful in dealing with these two types of matters.

4) It is wrong to analyze Arab world as though they represent one ideological and social fabric. Hence, the uniqueness of each society must be represented by the model.

Thus, efforts of Arab Anthropologists should not be limited to describe the Arab system by relying on Western theoretical concepts, or by collecting ethnographic data. Anthropological studies should also include a thorough examination of their heritage and identify authors who have gathered information from their relatives, and their religious teachings, from the people who considered these as the basis of their writings. Here, the mental life of nonWesterners, as Tawfiq al-Taweel noted, is strongly interwoven with their religious concepts, rather than with pure philosophical reflection and analyses the commonly used methodological approaches. This interpretation has been closely related with religious thought throughout all ages of civilization to such an extent that we can confidently say that any attempt to distinguish between them will fail to understand one or the other (Fahim, 1986, p. 72).

\section{The Future of Anthropology in the Arab World}

The future will provide Anthropology with new, and previously unimagined, opportunities. Moreover, Anthropologists' contributions will become more for human society than they have ever been before. To this end, Anthropology should expand its field of view, and prepare to respond to these opportunities, instead of preoccupying itself with issues of modernization. 
It is important to revise some of its deeply-rooted concepts and assumptions that have long been employed, unchanged and without discussion, regarding issues related to modernization and the ready adoption of Western influences due to globalization. It is to look for new ways to address the world we live. Therefore, using our Anthropological knowledge, we should continue studying the origins of Arab states, their organization, and their development (Obaid, 2004, pp. 301-02).

In order to survive in the contemporary Arab world academy, Anthropology should resume its former role and concentrate on asking questions that may attract the interest of a broader spectrum of people, and not only professional Anthropologists. It can be considered as a form of popularization. In this regard, many studies indicate that we should expect scientific progress in the fields of curricula, technologies, and audio-visual capabilities. These essential tools will be improved in the future. Small computers, and especially laptops, will provide field researchers with a more powerful means of simultaneously recording and analyzing information. All these developments have helped the Anthropological researchers to obtain and develop more sophisticated analytical tools. There is no doubt that further utilization of mathematics in the field of Anthropology will occur in the future (ibid., p. 304).

On the other hand, a vision of Anthropology's future should not be understood as an endeavor to define science that provides consistent and readily available information about the future. It is science that helps individuals to develop their capabilities for transforming the usual cognitive forms of thinking, steeped in the local cultural spirit, toward a broader culture and knowledge that depends on interactions, and non-pyramidal exchanges between all cultures, where technology is employed to remedy problems in current situations (Ibrahim, 1997, pp. 251-152).

In the future, Anthropology will be distinguished by a growing interest in urban industrial societies and postindustrialized societies and will utilize the early and large volumes of archival information to attain a better understanding of our civilization and daily lives. The importance of the Arab world has pushed it to the point that it has become an axis of struggle that will be characterized by increasing problems related to development and poverty. The emergence of new type of sub-specialization is not limited to feminist Anthropology. Instead, there are new subfields across Anthropological spectrum such as; the Anthropology of disease and epidemics, Anthropology centered on aging and the retired. Also applied Anthropology will be developed on cultural resources administration, cultural relativity, and human rights (Obaid, 2004, p. 323).

Despite these concerns and the diversity of Anthropological sub-disciplines, we should not conceal our fears regarding the problems that currently confront Arab Anthropology, and which are likely to impact its future trajectory. These problems can be summarized as follows:

1) At present, the level of cooperation among Arab Anthropologists is weak, despite the importance of dealing deftly with social and cultural phenomena. It is known that the problems we face are bound together to such an extent that cooperation and joint scientific work between social and Anthropological specialists is a condition for treating these problems. However, this requirement is still limited by different obstacles, some of which are related to Anthropologists who are so specialized that they have a narrow view of the field (Salim, 1999, p. 702).

2) International movements intended to change the political, social, and economic conditions in Arab societies have created huge problems that require social and psychological adaptations. Adaptations cannot be affected spontaneously or automatically; they need to be informed by well-planned Anthropological studies. Psychological, social, intellectual, behavioral, and other modes of a disorder are among the most prominent problems that will challenge Anthropological research in future (al-Norri, 1985, p. 34).

3) Understanding Anthropologyas a theoretical discipline concerned with primitive societies has led Arab decision makers to ignore Anthropological studies when facing various social and cultural problems. Hence, Arab Anthropologists must counter this attitude, and become far more involved in studying contemporary issues and providing practical solutions (ibid., 36).

4) Anthropological research has failed to explain some social events accurately; these findings were inaccurate to the degree that it would be difficult to predict whether they will have any utility (Salim, 1999, p. 704).

Providing explanations is difficult given the diversity of societal structures, and even inside the groups themselves. There is another factor that causes Anthropological research itself to overlook the real forces precipitating these phenomena. Consequently, it is necessary that Anthropological research formulates a futuristic vision that will bring emerging knowledge and the reasons that led to its change. This can often take the form of an explanatory vision that encapsulates the changes taking place in society, rather than considering change as one of the most important influences in social crises. Though change is often the main subject in Anthropological research, it is important not to study change and its role in the developmental framework without looking at other social aspects. 
The key task of applied Anthropologists is to present information to decision-makers and executives to improve their capabilities for planning work for achieving important general goals. This includes social crises management, documenting crises, training, guidance, monitoring, and control. Applying the results of all branches of Anthropology geared to serving humankind is pivotal. Anthropology's applications include many fields, the most important of which are learning and education, urbanization and population studies, and social and economic development. The important among them are the development of local societies, medical and public health fields, psychology, media, communications, TV, and radio programs, theater and literature, the arts, folklore, and ethnological museums. Anthropology also has relevance to industrial fields, military and psychological warfare, politics and administrative problems, crime and prisons.

Moreover, Anthropology of crises in the future, a sub-discipline concerned with the need for interventions, is expected to find solutions and reform what has been corrupted by deficiencies in the social order. Consequently, it is not a research of strategic implementation, though in both cases it aims at protecting society from problems and crises in the framework of group objectives that correspond with the prevailing culture. This obviates the need to;

1) Obtain accurate information documenting the society's issues and problems

2) Recognize the crises which may happen in future, and develop a perspective on possible crises

3) Recognize the prevailing context at the time of a crisis, find solutions and alternatives, and define which decisions require direct and rapid resolution.

These attitudes promise that Arab Anthropology will have a prosperous future, provided that it deepens its Arab identity, whether in its theoretical basis or in its applied objectives and should avoid transferring subjects without criticism. If Anthropology achieves this goal, it can reinforce its Arab originality and its international contributions to this field. Carleton S. Coon emphasized the fact that Arabs should have their projects and find the means to promote progress, and that the study of Anthropology can greatly help developing daily life in society, and improve the economy (Fahim, 1986, p. 269). There is no doubt that Arab Anthropology will be directed towards assisting Arab society and will contribute to its progress, corresponding with the advances in different social sciences. After all, ignorance of these sciences, especially from an Anthropological perspective, still prevails to some extent, and hinders serious and objective studies of the nature of other societies and may eventually lead to a better and real understanding of the nature and magnitude of the Arab contribution to culture (ibid., p. 270).

Therefore, this is a call to open up the Arab cultural windows into other cultures, especially those cultures that can be used fruitfully as examples that harmonizes with the essence of Arab character and cultural constituents. Area of focus of Arab Anthropologists includes the intellectual currents, attitudes, artistic and literary doctrines, and choosing what is suitable while ignoring the myth of cultural invasion. That is because all cultures develop, progress, and prosper, through communication, contact, exchanged influences, borrowing, and understanding. Contemporary Arab Anthropological studies should establish a relationship between Arab civilization and universal culture, and apply elements of Anthropological theory that correspond to the nature of Arab society, and its cultural, demographic, and historical structure (al-Shammas, 2004, pp. 175-76).

In addition, collaborative fieldwork, which consists of a group of ethnography specialists and reporters who work together to understand a society, is expected to be the future trend of ethnographic study, and, consequently, collaborative research will lead to collecting material and presenting hypotheses in a more organized way (Obaid, 2004, p. 330).

The problem that Arabs in the present millennium may face is not a technological problem. The crisis that Arabs suffered in the past, and which may loom in the future, is a result of the absence of strategic centers tasked with dealing with the future. This can be seen in the recent non-qualification and non-adaptation of Arabs in dealing with modernization, and the difficulty which they face in understanding current aspects of post-modernization. We need, more than ever before, to establish a science of future ethnography, through which we can define how we will deal with the challenges we are going to face in the future, as well as the types of expectations we have, and the ambitions we wish to achieve (ibid., pp. 332-33).

As a result of the misunderstanding of Arab decision-makers about the role of Anthropology, social problems no longer form the main core of Arab Anthropological research, although it presents findings and recommends practical solutions for those issues and problems. Hence, Arab Anthropology has not progressed to become more than a purely Anthropological body of knowledge, despite its ability to offer practical solutions that could help Arab societies to deal with various adverse issues. Arab Anthropologists must become involved in analyzing, understanding, and solving social issues and problems faced by individuals. This goal can be achieved by an approach characterized by a traditional study of social problems. 
Rather it entails providing the sound planning and guidance needed to face those factors causing the social crises, within the framework of its theoretical formation that corresponds to the nature of the crisis (Salim, 1999, p. 691).

The next point of discussion is the exact role of "Crisis Anthropology" in the society. Interventions in cases of violence in general are critical for the welfare of the society, because they are a diversion that represents an essential transition point in the phenomenon of development. It is usually of utmost complexity and intricacy whichrequires an intervention to prevent more negative incidents, and a deterioration to the extent that it may lead to threatening the social system.

\section{Conclusion}

The purpose of this paper was to explore the history and development of Anthropology in the Arab world and summarize the attempts that have been made to present a prospective vision of Anthropology in our Arab world for today and tomorrow. The paper also acknowledged Arab pioneer scholars in Anthropology on the nature of the topics they explored and the extent to which these thematic foci meshed with the subjects and issues of the discipline of Anthropology. The paper found that there is a strong connection between Anthropology and Arab society, given the various Anthropological studies that were produced under this framework, and the contributions it has made to deal with Arab society's issues and problems. Its contributions to this society's development and modernization are also highlighted.

One of the most important findings of this paper was that the confused political and social structure of Arab world including separation, decomposition, sectarianism, and fanaticism is the same structure whose dimensions and consequences were diagnosed by the Anthropologists. Thus, there remains a need for further studies. Anthropology's future in the Arab world depends on the extent to which the amount of practical solutions to the societal problems and needs which Anthropology can provide. In addition to the need for a new Anthropological vision and new methodological approaches, there is also a need for stronger and deeper applied Anthropology, and an expansion of the challenging subfield called the Anthropology of crisis.

\section{References}

Abo-Zaid, Ahmad (1980), Social Structure: Introduction to Study the Society. Dar al-Kitab al-Arabi Publication, Cairo.

Asad, Tala (1970), The Kababish Arabs: Power, Authority, and Consent in a Nomadic Tribe. C. Hurst \& Co. Publishers, London.

al--Awamlah, Nael (1995) Scientific Research Methods. Theoretical Bases and Applications. University of Jordan Press: Amman.

Badawi, Ahamd (2012) The Scientific Sociological Creation in the Arab Orient: Teaching and Research of Sociology in Egypt and Sudan. al-Mustaqbal al Arabi, 35 (400): 131-153.

Baqader, AboBaker\& Hassan Rashiq (2012) Anthropology in the Arab World. Dar al-Fiker al-Arabi Publications: Amman.

Barth, Fredrik (1983), Sohar, culture and society in an Omani town. Baltimore: Johns Hopkins University Press. al-Jibawi, Ali (1997). Anthropology-Science of Mankind. Damascus University Publication, Damascus.

al-Jawhari, Mohamad et al. (2005) Contemporary Studies in Social Anthropology. Dar al-Marifa Publication: Cairo.

Cunnison, Ian (1966), Baffara Arabs: Power and the Lineage in a Sudanese Nomad Tribe. Oxford University Press, Oxford.

Fahim, Hussain (1986) The Story of Anthropology: Chapters in Human Science History. Alam al-Ma'arifa, 98, Kuwait. Huntington, Samuel P. (1996), The Clash of Civilizations and the Remaking of World Order, Simon \& Schuster, New York HussainMoenis (1978) Civilization: A Study in Its Origin and Creation and Factors of Decline. Issue \#1, National Council for Culture, Arts \& Letters, Kuwait.

Ibrahim, Ftaiha (1997) Anthropological Vision of Some Problems in Our Contemporary World. King Saud University Journal, 9 (1): 231-257.

Ismael, Zaki (1997) Features of Anthropological Studies in the Heritage of Muslim Intellectuals, The College of Social Sciences Journal, 1 (1): 291-225.

Jurmain, Robert, Lynn Kilgore, Wenda Trevathan (2009) Essentials of Physical Anthropology Seventh Edition. Wadsworth: USA. 
Kluckhohn, Clyde (1949) Mirror for Man: The Relation of Anthropology to Modern Life.University of Arizona Press: Tempe, AZ.

Kossa, Nourdin (2015) The Anthropology of Al-Mghrib Al-Arabi. Mohammad Lameen Dabaghin University Press: Staif, AlGeria.

al-Madani, Khalil (2007) Sociology in the Arab World: Reality and Ambition. Symposium on Sociology from an Islamic Perspective. Center of Cognitive Studies: Cairo.

al-Mikawi, Ali (2008) Studies in Applied Anthropology. Dar al-Nasser Publication and Distribution: Cairo.

Mohammad Riyadh (1974), Man: A Study in Gender and Civilization. Dar al-Nah'dah al-Arabiya, Lebanon.

Mohammad, Samiaet al. (2003) Scientific Social Research. Dar al-Ma'arifa al-jami’yah Publications: Cairo.

al-Norri, Qais (1985) Social Problems in the Arab World from an Anthropological Perspective. Institute of Arabic Studies and Researcher Journal, 14 (3): 16-39.

Obaid, Mohamed (2004) Anthropology Futuristic Image and the $21^{\text {st }}$ Century Challenges. College of Arts Journal, 2 (34): 285-350.Riyadh, Mohammad (1974), Man: A Study in Gender and Civilization. Dar al-Nah'dah alArabiya, Lebanon.

Safouh Al-Akhras (1984), Social Anthropology. Damascus University Publication, Damascus.

Saleh, Nahed, ed. (2002) Research in Arabic Anthropology. Social Studies and Research Center, College of Arts, Cairo University: Cairo.

Salim, Abdul Samad (1999) Anthropology of Crises and Violence: A Case Study of Social Crises. The $4^{\text {th }}$ Annual Conference for the Crises and Disasters Management, vol. 1, 690-724.

al-Shammas, Essa (2004) Introduction to Anthropology. The Arab Writers Publications: Damascus.

Wasfi, Atif (1971), Cultural Anthropology, Dar al-Nah'da al-Arabiya, Lebanon.

Zarqana, Ibrahim (1958), Anthropology, al-Nah'da al-Masriya Books, Cairo.

al-Zuabi, Ali (1999) Urbanization, Tribalism and Contemporary Tribal Marriage in Kuwait. Unpublished Dissertation. Wayne State University, Detroit. 